\title{
Determinan Insomnia pada Lanjut Usia
}

\author{
Determinant of Insomnia on Elderly
}

\author{
Andi Zulkifli Abdullah* A. Arsunan Arsin* Muhammad Yahya**
}

\begin{abstract}
*Bagian Epidemiologi Fakultas Kesehatan Masyarakat Universitas Hasanuddin, **Dinas Kesehatan Kabupaten Bone Bolango
\end{abstract}

\begin{abstract}
Abstrak
Insomnia merupakan gangguan tidur yang paling sering ditemukan pada lanjut usia (lansia) dengan prevalensi sekitar $67 \%$. Penelitian ini bertujuan untuk menilai hubungan antara kecemasan, depresi, dukungan keluarga, dan kondisi lingkungan dengan kejadian insomnia pada lansia di Panti Sosial Tresna Werdha Gau Mabaji Kabupaten Gowa. Penelitian ini menggunakan desain studi observasional dengan rancangan cross sectional dan metode exhausive sampling. Data dianalisis dengan uji chi square, koefisien phi (f) dengan $a=0,05$. Sebanyak 96 lansia penghuni panti memenuhi kriteria penelitian. Uji chi square menunjukkan bahwa terdapat hubungan antara kecemasan (nilai $p=0,014 ; f=0,251)$, depresi (nilai $p=0,019 ; f=$ 0,238 ), dukungan keluarga (nilai $p=0,000$ ); $f=0,797$ ), dan kondisi lingkungan panti (nilai $p<0,05 ; f=0,238$ ) dengan kejadian insomnia. Pemberian penyuluhan kepada keluarga lansia adalah salah satu kegiatan yang penting dilakukan untuk meningkatkan pengetahuan keluarga lansia bahwa lansia tidak hanya sekadar diperhatikan kebutuhan fisiknya tetapi juga kebutuhan psikologisnya.
\end{abstract}

Kata kunci: Depresi, insomnia, kecemasan

\footnotetext{
Abstract

Insomnia is sleep disorder, most often found on elderly with high prevalence about $67 \%$. The aim of this research is to prove the relation between anxiousness, depression, family support, and environmental condition with the occurence of insomnia at old ages in social institution Tresna Werdha Gau Mabaji Gowa Regency. This research used an observasional study with cross sectional design, using the exhausive sampling method. Data were analysed by chi square test, phi coefficient with $a=0,05$. About 96 elderly in social institution met the research criteria, chi square test indicates that there are relation between anxiousness ( $p$ value $=0,014) ; f=0,251$ ), depression ( $p$ value $=0,019) ; f=0,238)$, family support ( $p$ value $=0,000) ; f$ $=0,797$ ), and environmental condition of social institution ( $p$ value $=0,019$ ); $f=0,238$ ) with the occurence of insomnia. Providing counseling to the fami-
}

ly of the elderly is one of the important activities to improve their knowledge to note not only elderly physical needs, but also their psychological needs. Keywords: Depression, insomnia, anxiousness,

\section{Pendahuluan}

Populasi lanjut usia (lansia) yang hadir secara mendadak dalam jumlah besar akan berimplikasi khusus terhadap dunia kesehatan. Pada tingkat lansia, individu banyak mengalami perubahan secara biologis, psikologis, dan sosial, khususnya kemunduran berbagai fungsi dan kemampuan yang dahulu pernah dimiliki. ${ }^{1}$ Proses penuaan antara lain perubahan penampilan fisik, penurunan daya tahan tubuh, dan penurunan berbagai fungsi organ mengancam integritas lansia. Mereka juga harus berhadapan dengan kehilangan peran diri, kedudukan sosial, serta perpisahan dengan orang-orang yang dicintai. Kondisi tersebut menyebabkan seorang lansia lebih rentan untuk mengalami berbagai masalah kesehatan termasuk gangguan tidur. ${ }^{2}$ Insomnia merupakan gangguan tidur yang paling sering ditemukan pada lansia. Setiap tahun diperkirakan sekitar $20 \%-50 \%$ orang dewasa melaporkan gangguan tidur dan sekitar 17\% mengalami gangguan tidur yang serius. Prevalensi gangguan tidur pada lansia tergolong tinggi yaitu sekitar $67 \% .^{3}$ Gangguan mental yang berhubungan erat dengan gangguan tidur adalah kecemasan yang menyebabkan kesulitan mulai tidur, lama masuk tidur (lebih dari 60 menit), mimpi menakutkan, kesulitan bangun pagi, dan bangun

\footnotetext{
Alamat Korespondensi: Andi Zulkifli Abdullah, Bagian Epidemiologi FKM Universitas Hasanuddin, Jl. Perintis Kemerdekaan Km. 10 Tamalanrea Makassar 90245, Hp.081342706750,e-mail: zulkifliabdullah@yahoo.com
} 
di pagi hari kurang segar. ${ }^{4}$ Penelitian Epidemiologic Catchment Area di Amerika Serikat menemukan 25\% lansia mengalami kecemasan yang disebabkan oleh gangguan tidur. ${ }^{5}$

Gangguan mental lain yang berhubungan dengan gangguan tidur adalah depresi yang dapat menyebabkan masuk tidur memerlukan waktu 15 - 60 menit, mimpi yang menyedihkan tentang kesendirian dan kesepian, terbangun dini hari dan sulit tidur kembali, serta merasa lesu ketika terbangun. ${ }^{4}$ Sekitar $85 \%$ dari pasien insomnia tersebut mengalami satu atau dua skala Minnesota Multiphasic Personality Inventory yang cenderung meningkat ke arah patologi dan yang terbanyak adalah depresi. ${ }^{6}$

Sistem pendukung utama lansia adalah keluarga karena ketika menghadapi masalah, alternatif pertama tempat lansia meminta pertolongan adalah keluarga, setelah itu alternatif yang lain meliputi teman, tetangga, dan tempat pelayanan sosial. Penelitian sebelumnya menemukan bahwa sekitar 35\% lansia yang tinggal di Panti Sosial Tresna Werdha Gau Mabaji Kabupaten Gowa mengalami gangguan tidur karena kurang mendapat dukungan keluarga. ${ }^{7}$ Lansia sangat sensitif terhadap stimulus lingkungan seperti suara gaduh, cahaya, dan temperatur. Penggunaan tutup telinga, tutup mata, dan alas tidur yang tidak nyaman dapat mengganggu tidur. Lansia dengan gangguan tidur, yang merupakan penyebab morbiditas, mengalami peningkatan jumlah tidur pada siang hari sehingga memicu kecemasan dan depresi pada malam hari. Kekurangan tidur yang panjang dapat menyebabkan disorganisasi ego, halusinasi, dan waham. ${ }^{3}$ Data Panti Sosial Tresna Werdha Gau Mabaji Kabupaten Gowa pada akhir bulan Juli tahun 2007 mencatat bahwa dari 100 orang lansia penghuni panti terdapat 35 orang lansia yang mengeluhkan gangguan tidur. ${ }^{7}$ Penelitian ini ditujukan untuk mengetahui hubungan antara kecemasan, depresi, dukungan keluarga, dan kondisi lingkungan panti dengan kejadian insomnia pada lansia.

\section{Metode}

Penelitian dilakukan di Panti Sosial Tresna Werdha Gau Mabaji Kecamatan Bontomarannu Kabupaten Gowa dengan pertimbangan banyak penghuni mengalami keluhan gangguan tidur dan populasi yang cukup besar. Populasi penelitian adalah semua lansia berumur 60 tahun ke atas dan sampel adalah semua lansia yang berumur 60 tahun ke atas dan menetap di Panti Sosial Tresna Werdha Gau Mabaji saat penelitian dilaksanakan. Sampel ditarik menggunakan metode exhautive sampling dengan menjadikan semua lansia penghuni panti sebagai sampel. Sumber data meliputi data primer dan sekunder. Data primer dikumpulkan dari wawancara terhadap lansia menggunakan kuesioner terstruktur dan data sekunder diambil dari profil Panti Sosial Tresna Werdha Gau
Mabaji yang didapatkan dari instansi terkait. Kegiatan pengumpulan data dilakukan pada bulan Juni tahun 2008. Variabel yang diteliti meliputi variabel bebas yaitu kecemasan, depresi, dukungan keluarga, kondisi lingkungan panti; dan variabel terikat yaitu kejadian insomnia. Analisis data yang dilakukan meliputi analisis univariat untuk melihat gambaran deskriptif dari setiap variabel penelitian, dan analisis bivariat untuk melihat hubungan antara masing-masing variabel independen dengan variabel dependen dengan menggunakan uji chi square dan koefisien phi $(\phi)$.

\section{Hasil}

Distribusi penderita berdasarkan kelompok umur memperlihatkan bahwa lansia terbanyak pada kelompok umur $71-75$ tahun $(29,2 \%)$ dan $76-80$ tahun $(24,0 \%)$ serta yang terendah pada kelompok umur $<65$ tahun $(11,5 \%)$ (Tabel 1).

Proporsi lansia yang mengalami kecemasan dan menderita insomnia sekitar $86,4 \%$. Analisis bivariat menemukan nilai $\mathrm{p}=0,014$ lebih kecil daripada nilai $\alpha(0,05)$ dan nilai $\phi=0,251$. Hasil tersebut menyatakan hubungan yang lemah, kecemasan berkontribusi sekitar 25,1\% terhadap kejadian insomnia. Selanjutnya, sekitar $88,1 \%$ lansia yang mengalami depresi menderita insomnia, nilai $p=0,024$ lebih kecil daripada nilai $\alpha$. Hal tersebut mengindikasikan hubungan depresi dengan kejadian insomnia, tetapi dengan nilai $\phi=0,230$ menyatakan hubungan yang lemah. Depresi berkontribusi sekitar 23,0\% terhadap kejadian insomnia. Sekitar 97,4\% lansia yang tidak mendapatkan dukungan keluarga menderita insomnia dengan nilai $p=0,000$ yang lebih kecil daripada nilai $\alpha$. Dengan demikian, dukungan keluarga berhubungan sangat kuat dengan kejadian insomnia berdasarkan nilai $\phi=0,797$ yang berarti bahwa dukungan keluarga berkontribusi sekitar 79,7\% terhadap kejadian insomnia. Selanjutnya, sekitar 92,2\% lansia yang merasa terganggu dengan kondisi lingkungan panti menderita insomnia. Berdasarkan uji fisher didapatkan nilai $\mathrm{p}=0,000$ yang lebih kecil daripada nilai $\alpha$. Temuan ini mengindikasikan hubungan yang secara statistik bermakna antara kondisi lingkungan panti dengan kejadian insomnia. Berdasarkan nilai $\phi=0,367$ memperlihatkan bahwa hubungan terse-

Tabel 1. Distribusi Lansia Berdasarkan Kelompok Umur

\begin{tabular}{lcc}
\hline Kelompok Umur & Jumlah & Proporsi $(\%)$ \\
\hline$\leq 65$ tahun & 11 & 11,5 \\
$66-70$ tahun & 15 & 15,6 \\
$71-75$ tahun & 28 & 29,2 \\
$76-80$ tahun & 23 & 24,0 \\
$\geq 81$ tahun & 19 & 19,8 \\
\hline Total & $\mathbf{9 6}$ & $\mathbf{1 0 0 , 0}$ \\
\hline
\end{tabular}


Tabel 2. Hasil Analisis Bivariat Insomnia pada Lansia di Panti Sosial Tresna Werdha Gau Mabaji Tahun 2008 Kabupaten Gowa

\begin{tabular}{lllllll}
\hline & & \multicolumn{3}{c}{ Kejadian Insomnia } \\
\cline { 3 - 5 } Variabel & Kategori & \multicolumn{2}{c}{ Ya } & \multicolumn{2}{c}{ Tidak } & \multirow{2}{*}{ Nilai p } \\
\cline { 3 - 5 } & & n & $\%$ & n & $\%$ \\
\hline \multirow{2}{*}{ Depresi } & Ya & 70 & 86,4 & 11 & 13,6 & 0,014 \\
& Tidak & 9 & 60,0 & 6 & 60,0 & 0,251 \\
Kecemasan & Ya & 59 & 88,1 & 8 & 11,9 & 0,024 \\
Dukungan keluarga & Tidak & 20 & 69,0 & 9 & 31,0 & 0,251 \\
& Ya & 20 & 62,5 & 12 & 37,5 & 0,367 \\
& Tidak & 75 & 97,4 & 2 & 2,6 & 0,000 \\
& Terganggu & 4 & 21,1 & 15 & 78,9 & 0,797 \\
& Tidak terganggu & 59 & 92,2 & 5 & 7,8 & 0,000 \\
\hline
\end{tabular}

but termasuk dalam kategori sedang. Kondisi lingkungan panti diperkirakan berkontribusi $36,7 \%$ terhadap kejadian insomnia (Tabel 2).

\section{Pembahasan}

Kelemahan penelitian dengan desain cross sectional ini adalah penyebab tidak dapat dipastikan mendahului akibat, variabel depresi dan kecemasan tidak dapat dipastikan mendahului kejadian insomnia. Keadaan dapat terjadi sebaliknya bahwa insomnia menyebabkan kecemasan dan depresi. Kelemahan kecemasan adalah perasaan yang tidak menyenangkan atau ketakutan yang tidak jelas dan terjadi sebagai reaksi terhadap sesuatu yang dialami oleh seseorang. ${ }^{4}$ Gangguan mental yang berhubungan erat dengan kejadian insomnia adalah kecemasan yang menyebabkan kesulitan mulai tidur dan waktu masuk tidur lama (> 60 menit). Penderita mengalami mimpi menakutkan, sulit bangun pagi hari, serta merasa tidak segar. ${ }^{8}$ Penelitian Epidemiological Catchment Area di Amerika Serikat menemukan sekitar $25 \%$ lansia mengalami kecemasan akibat gangguan tidur. ${ }^{5}$ Gejala-gejala kecemasan yang umum terjadi pada lansia adalah bicara cepat, meremas-remas tangan, bertanya berulang-ulang, tidak mampu berkonsentrasi atau tidak mengerti penjelasan, tidak mampu menyimpan berbagai informasi yang diberikan, gelisah, keluhan pada tubuh, serta kedinginan dan telapak tangan lembab. Kecemasan tentang masalah atau situasi pribadi menyebabkan seseorang menjadi tegang dan sering mengarah kepada frustrasi yang menyebabkan sulit tidur dan sering terbangun selama siklus tidur. Untuk mengatasi kecemasan dan kekhawatiran yang dialami lansia, penyebab yang mendasari perlu dibahas dan coba diungkap. Eliminasi penyebab dan pemberian rasa aman perlu diupayakan dengan penuh empati. Apabila penyebab tidak ditemukan atau tidak jelas, sebaiknya diberikan berbagai alasan yang dapat diterima. Selain itu, dalam proses meyakinkan kembali dan menjelaskan kekhawatiran yang dialami perlu melibatkan anggota keluarga atau te- man para lansia. ${ }^{9}$

Depresi adalah perasaan sedih dan pesimis yang berhubungan dengan suatu pengalaman yang tidak menyenangkan, dapat berupa serangan yang ditunjukkan pada diri sendiri atau perasaan marah yang mendalam. ${ }^{4}$ Depresi merupakan masalah kesehatan jiwa yang paling sering ditemukan pada lansia dengan gejalagejala meliputi gangguan tidur atau cepat terbangun pada dini hari; kelelahan, lemas, dan kurang menikmati kehidupan sehari-hari; mengabaikan kebersihan dan kerapihan diri; cepat marah dan tersinggung; topik pembicaraan yang pesimis atau putus asa; nafsu makan berkurang atau hilang sehingga berat badan menurun cepat; dalam pembicaraan cenderung menyatakan ingin bunuh diri. 6

Mengenal depresi pada lansia memerlukan keterampilan dan pengalaman karena manifestasi gejala depresi klasik seperti perasaan sedih, kurang semangat, kehilangan minat, hobi atau aktivitas menurun sering tidak muncul. Lansia yang mengalami depresi dapat mengeluhkan suasana hati yang menurun, tetapi kebanyakan menyangkal suasana hati depresi. Gejala yang sering terlihat adalah hilang tenaga, hilang rasa senang, tidak dapat tidur atau keluhan rasa sakit. Gejala depresi yang sering tampil adalah kecemasan, gejala fisik, mencela diri, pikiran bunuh diri, dan insomnia. Penelitian Minnesota Multiphasic Personality Inventory terhadap para penderita dengan keluhan utama insomnia ternyata menghasilkan $85 \%$ pasien insomnia dengan 1 atau 2 skala MMPI cenderung meningkat ke arah patologis dan yang terbanyak adalah depresi. Tindakan untuk mengatasi depresi pada lansia antara lain meluangkan waktu untuk bercakap-cakap bersama lansia, memberi motivasi bahwa peristiwa yang dialami dapat membawa manfaat dan dapat ditanggulangi dengan baik, serta melibatkan anggota keluarga mengenai peristiwa yang dialami lansia. ${ }^{9}$ Depresi dapat menjadi penyebab atau sebaliknya justru menjadi akibat atau dapat juga merupakan kausalitas melingkar yang dapat diketahui melalui studi literatur 
atau penelitian lebih lanjut dengan desain longitudinal.

Keluarga merupakan sistem pendukung utama bagi lansia. Apabila terjadi suatu masalah, keluarga menjadi tujuan pertama lansia untuk meminta pertolongan, setelah itu teman dan tetangga, sedangkan tempat pelayanan sosial merupakan pilihan terakhir. ${ }^{10}$ Selain itu, dukungan keluarga dalam kehidupan lansia sangat penting terutama jika terjadi perubahan fisik atau fungsi mental lansia dan keluarga memegang tanggung jawab untuk menolong lansia mengidentifikasi masalahnya dari berbagai sumber. Beberapa hal yang dapat dilakukan dalam melaksanakan peran anggota keluarga terhadap lansia yaitu mempertahankan kehangatan keluarga, bersikap sabar dan bijaksana terhadap perilaku lansia, serta tidak dianggap sebagai beban. ${ }^{9}$

\section{Kondisi Lingkungan Panti}

Perpindahan tempat tinggal bagi lansia merupakan pengalaman traumatis karena pindah tempat berarti mengubah berbagai kebiasaan yang selama ini dilakukan oleh lansia di lingkungan tempat tinggal. Selain itu, dengan pindah tempat tinggal berarti lansia kehilangan teman dan tetangga yang selama ini berinteraksi serta memberikan rasa aman pada lansia. Kondisi ini tidak dialami oleh semua lansia karena pindah tempat tinggal yang telah dilakukan dengan persiapan yang memadai dan perencanaan yang matang terhadap lingkungan baru bagi lansia diperkirakan berdampak positif bagi kehidupan lansia. Lingkungan panti dapat memberikan kesenangan bagi lansia. Sosialisasi di lingkungan yang mempunyai tingkat usia sebaya akan menjadi hiburan tersendiri sehingga kebersamaan ini dapat mengubur kesepian yang biasa mereka alami. ${ }^{9}$

Suara yang lembut sering memudahkan memulai tidur, sementara suara yang keras dapat membangunkan pada tahap tidur stadium tiga dan empat. Beberapa orang membutuhkan ketenangan, sedangkan sebagian lainnya lebih menyukai suara yang lembut sebagai latar belakang untuk memulai tidur seperti musik yang lembut. Suara di panti biasanya asing dan menciptakan masalah bagi lansia seperti sulit memulai tidur dan mudah terbangun. Sekitar 45\% lansia yang tinggal di Panti Sosial Tresna Werdha Gau Mabaji Kabupaten Gowa mengalami gangguan tidur karena kurang dukungan keluarga. ${ }^{7}$ Agar kondisi lingkungan panti tetap kondusif bagi lansia diper- lukan modifikasi lingkungan antara lain menciptakan suasana tenang dan nyaman, menggunakan cahaya yang agak redup, dan menghindari cahaya langsung.

\section{Kesimpulan}

Hasil penelitian menunjukkan bahwa hasil analisis bivariat memperlihatkan hubungan yang secara statistik bermakna antara kecemasan depresi, dukungan keluarga, dan kondisi lingkungan panti dengan kejadian insomnia pada kelompok lansia yang tinggal di Panti Sosial Tresna Werdha Gau Mabaji Kabupaten Gowa.

\section{Saran}

Hasil penelitian ini diharapkan dapat menjadi bahan masukan bagi penyusunan program kegiatan di Panti Sosial Tresna Werdha Gau Mabaji Kabupaten Gowa. Pemberian penyuluhan kepada keluarga lansia merupakan kegiatan yang perlu dilakukan untuk meningkatkan pengetahuan keluarga bahwa lansia membutuhkan tidak hanya perhatian pada kebutuhan fisik, tetapi juga kebutuhan psikologis.

\section{Daftar Pustaka}

1. Surilena. Faktor-faktor yang mempengaruhi depresi pada lansia di Jakarta. Majalah Kedokteran Damianus. 2006; 5 (2): 115-29.

2. Stanley M, Beare GP. Buku ajar keparawatan gerontik. 2nd ed. Jakarta: EGC; 2007.

3. Amir N. Gangguan tidur pada lanjut usia diagnosis dan penatalaksanaannya. Cermin Dunia Kedokteran. 2007; 34 (4/157): 196.

4. Nugroho W. Keperawatan gerontik. 3rd ed. Jakarta: EGC; 2004.

5. Henuhili S, Wibisono S, Pleyte EH, Prihartono J. Proportion of mental disorders among the elderly residence of Sasana Tresna Werda yayasan Karya Bakti Ria Pembangunan Cibubur. Majalah Kedokteran Indonesia. 2005; 55 (10): 639-49.

6. Hardiman A. Insomnia: suatu tinjauan kesehatan jiwa. Majalah Dokter Keluarga. 2004; 8 (2): 107-12.

7. Barangkau. Analisis faktor-faktor yang mempengaruhi pemenuhan kebutuhan tidur pada lansia di PSTW Gau Mabaji Gowa [skripsi]. Makassar: Universitas Hasanuddin; 2007.

8. Gunawan. Gangguan sakit tidur (insomnia). Jakarta: Kanisius; 2001.

9. Maryam RS, Ekasari MF, Rosidawati, Jubaedi A, Batubara I. Mengenal usia lanjut dan perawatannya. Jakarta: Salemba Medika; 2008.

10. Jusni S. Buku pedoman kesehatan jiwa. Jakarta: Direktorat Jenderal Bina Kesehatan Masyarakat Kementerian Kesehatan Republik Indonesia; 2003. 